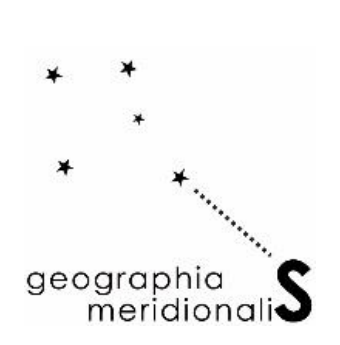

GeographiaMeridionalis - revista eletrônica do Programa de Pós-Graduação em Geografia da Universidade Federal de Pelotas

http://periodicos.ufpel.edu.br/ojs2/index.php/Geographis/index ISSN 2446-9165 Recebido em:07/03/2016 Revisões Requeridas em: 31/05/2016 Aceito em:31/05/2016

\title{
OS GRANDES EVENTOS ESPORTIVOS E A DINÂMICA IMOBILIÁRIA E HABITACIONAL: A NATUREZA E AS CONTRADIÇÕES DO PROGRAMA MINHA CASA MINHA VIDA (PMCMV) EM SÃO LOURENÇO DA MATA-PE
}

\author{
THE GREAT EVENTS SPORTS AND REAL ESTATE DYNAMICS AND \\ HOUSING: THE NATURE AND CONTRADICTIONS IN THE PROGRAM MINHA \\ CASA MINHA VIDA (PMCMV) IN SÃO LOURENÇO DA MATA-PE
}

Cleiton Ferreira da Silva Universidade Federal de Pernambuco Doutorando em Geografia cleitonf4@yahoo.com.br

\section{RESUMO}

Este trabalho debate a natureza e as contradições da política nacional de habitação popular, a partir de um viés histórico no Brasil, perpassando por mudanças recentes, desencadeando mais recentemente, no programa de construção de moradias denominado Programa Minha Casa Minha Vida (PMCMV). Para isso, analisamos empiricamente o município de São Lourenço da Mata, localizado na Zona Oeste da Região Metropolitana do Recife (RMR), cujos investimentos para receber jogos da Copa das Confederações e do Mundo, impulsionaram o crescimento imobiliário e a atuação das construtoras, com a anuência das três esferas governamentais (municipal, estadual e federal). Diante disso e a partir do levantamento em órgãos públicos e privados, entre os anos de 2008 e 2015, juntamente com o trabalho de campo, retratamos os empreendimentos subsidiados pelo PMCMV, suas principais características e as respectivas contradições no que concerne ao espaço geográfico local.

Palavras-chave: Política Pública; Habitação; Projetos Urbanos.

\begin{abstract}
This paper discusses the nature and contradictions of national social housing policy from a historical bias in Brazil, passing by recent changes, triggering more recently, the housing construction program known as Minha Casa Minha Vida (PMCMV). For this, empirically analyze the São Lourenço da Mata, located in the West Zone of the Metropolitan Region of Recife (RMR), whose investments to host matches of the Confederations Cup and the World, boosted the real estate growth and the performance of the construction, with the concurrence of the three levels of government (municipal, state and federal). Therefore, and from the survey of public and private agencies, between the years 2008 and 2015, along with the field work, we depict the projects subsidized by PMCMV, its main characteristics and their contradictions with respect to the local geographical area.
\end{abstract}

Keywords: Public Policy; Housing; Urban Projects. 


\section{1 - Introdução}

As políticas públicas de "habitação popular"” desenvolvidas no Brasil sofreram intensas modificações ao longo do tempo. Elas são resultantes de conjunturas políticas específicas, cuja perspectiva se baseia na tentativa de minimização do déficit habitacional que assola especialmente as grandes cidades, porém, há imensas contradições no que concerne à sua construção e implantação.

Baseando-se no principio da construção dos grandes conjuntos habitacionais, foi criado pela Lei n. 4.380 de 1964 o Banco Nacional de Habitação (BNH), tendo o Fundo de Garantia por Tempo de Serviço (FGTS) como o principal financiador do BNH. O Programa foi estruturado para atender as populações mais carentes, estando organizado sistematicamente a partir das Companhias Habitacionais (COHAB's), como forma de solucionar os problemas habitacionais, porém, o saldo é que foram políticas baseadas em mecanismos burocráticos de seleção das famílias e, com pouca efetividade no combate ao grande déficit habitacional no Brasil ao final do programa em 1986.

A introdução do modelo neoliberal pós-ditadura militar, paralisou significativamente os investimentos em políticas de caráter social, especificamente no que se destinava à habitação, entretanto, com o advento do governo Lula (2003-2010), houve o desenvolvimento do Programa Minha Casa Minha Vida (PMCMV), em meio à crise financeira internacional de 2008 e a necessidade de impulsionar o sistema imobiliáriofinanceiro no Brasil.

Este programa desencadeou a construção de milhares de habitações em todo o país, motivada pelo beneficiamento através do governo para as corporações imobiliárias, seja na redução de impostos e materiais de construção, seja na desburocratização da política de aquisição das moradias em bancos e instituições jurídico-financeiras. $\mathrm{O}$ fato, é que esta política teve uma repercussão e um impacto gradativo na organização socioespacial em diversas cidades brasileiras, especialmente, as de médio e grande porte.

Neste sentido, este trabalho discute e analisa o impacto das políticas de habitação popular, especialmente através do PMCMV em São Lourenço da Mata, município

\footnotetext{
${ }^{1}$ Optamos na colocação das aspas nas palavras habitação popular, em função do caráter contraditório que o termo foi adotado no Brasil, especialmente quando se refere à política pública de habitação para o seguimento de baixa renda (até 3 salários mínimos). Ver item que trata sobre o PMCMV no texto.
} 
integrante da Região Metropolitana do Recife (RMR), bem como a influência dos empreendimentos para atender a Copa de 2014 na consequente expansão dos projetos imobiliários.

Para isso, analisamos os dados dos projetos habitacionais aprovados entre os anos de 2008 e 2015, a partir do trabalho de campo e de coleta junto às construtoras envolvidas e à prefeitura municipal, destacando a distribuição espacial no município, os valores empregados, a quantidade de unidades, as contradições e o impacto na (re)organização do espaço. Promovendo, assim, um amplo debate sobre o modelo de política habitacional e suas contradições intrínsecas para o espaço geográfico analisado.

\section{2 - Antecedentes da política nacional de "habitação popular"}

O período conhecido como República Velha (1889-1930) ficou caracterizado pela força da iniciativa privada, uma vez que ela era a principal detentora dos mecanismos de construção, incorporação e administração das habitações das classes trabalhadoras, tendo os cortiços como exemplos mais comuns deste processo. Restava, portanto, aos órgãos governamentais a regulamentação e repressão às situações graves de insalubridade, através das legislações sanitárias e policiais, e a concessão de isenções fiscais, que beneficiavam, sobretudo os proprietários das casas (ROLNIK, 1997).

Com a falta de moradias e o elevado número de trabalhadores precarizados, cresceram substancialmente as moradias subnormais ou insalubres, ou seja, os mocambos, as estalagens, as vilas operárias, as favelas e os $\operatorname{cortiços}^{2}$, muito comuns nas cidades possuidoras do maior número de operários de baixa renda, como Rio de Janeiro e São Paulo (SIQUEIRA, 2008).

Os cortiços proliferam-se por grandes áreas, uma vez que a demanda por moradia, por parte das classes menos favorecidas era uma realidade. Pelo fato dos construtores não seguirem à risca as legislações que disciplinavam a construção das moradias e pela própria natureza das habitações que inviabilizavam a manutenção de um ambiente salubre, rapidamente passaram a representar um perigo para a saúde pública. Não foram

\footnotetext{
${ }^{2}$ Bonduki (2005) faz uma descrição detalhada acerca das condições socioeconômicas dos trabalhadores que habitavam os cortiços e da própria moradia neste período.
} 
raras as ações governamentais, com a participação dos sanitaristas e o apoio da polícia, de forma preconceituosa e autoritária nos cortiços, como retrata Bonduki (2005):

Os agentes da ordem sanitária não hesitaram em invadir casas, remover moradores (doentes ou não), desinfectar móveis e objetos pessoais, demolir e queimar casebres, isolar quarteirões, prender suspeitos, atacar focos (BONDUKI, 2005, p. 31).

A falta de moradias fez com que fosse observado outro tipo de modalidade de construção de casas populares, que se destinavam a atender os trabalhadores, ou seja, as chamadas vilas operárias, que funcionavam essencialmente, como mecanismos de controle social e como uma ação paternalista dos empresários para com os trabalhadores, como forma também de coibir mobilizações sociais (SIQUEIRA, 2008). O período descrito foi, portanto, marcado essencialmente pela participação da iniciativa privada na promoção e incorporação das chamadas casas populares e o aumento dos seus lucros. Houve, dessa forma, uma ausência do Estado no que concerne à provisão de políticas públicas de habitação.

Esse panorama político influenciou também as políticas da época, uma vez que a questão das moradias para os trabalhadores já era considerada um problema de ordem pública, sob parâmetros da concepção higienista. Entretanto, as intervenções só ocorreram efetivamente em 1937 com a criação de abrigos provisórios que se destinavam a atender os que se alojavam em locais caracterizados como favelas. $\mathrm{O}$ governo Vargas também criou as Carteiras Prediais, vinculadas ao sistema de previdência, Institutos de Aposentadoria e Pensões (IAPs) (SIQUEIRA, 2008). Apesar desse modelo se caracterizar em ações meramente pontuais; há o reconhecimento de sua importância, uma vez que elas representaram o início da construção de um modelo político de construção da habitação popular.

A Lei do Inquilinato de 1942 representou outro mecanismo de intervenção do governo neste período, instituindo o congelamento dos aluguéis no nível de 1941, além da regulamentação das relações entre proprietários e inquilinos (BONDUKI, 2005). Se por um lado, o congelamento dos preços dos aluguéis permitiu certa estabilidade, por outro, o despejo seria outra modalidade encontrada pelos proprietários para burlar a legislação, ou seja, aumentava-se o valor cobrado para a nova família que se instalaria no lugar. 
Esta situação aumentou o número de autoconstruções, em locais sem a mínima infraestrutura, como em morros, encostas, áreas de várzea, etc.

Em 1946, sob o governo Dutra, foi criado o primeiro órgão estatal, na esfera federal, chamado Fundação da Casa Popular com a incumbência de intervir diretamente no campo da habitação, através do atendimento e construção de casas para populações de baixa renda, além da elaboração de estudos de métodos para o barateamento das construções. O projeto sucumbiu pela dificuldade das famílias se adequarem aos editais e financiamentos conforme a renda, uma vez que era considerada alta para os padrões populares. Além disso, outros fatores contribuíram para a dificuldade do acesso à casa própria, como esclarece Lehfeld (1988):

[...] restrições de informações, de prazo, de número de inscrições e de moradia oferecidas. Os editais de divulgação não alcançavam a todos os interessados e os prazos para a inscrição nem sempre eram suficientes (LEHFELD, 1988, p. 25).

Atrelado a isso, esta política foi considerada clientelista na construção e triagem dos candidatos, muitos dos quais possuíam apadrinhamento político e não participavam do processo seletivo, além disso, o critério de escolha e de decisão de onde construir não era claro, nem tão pouco democrático (AZEVEDO \& ANDRADE, 1982). Logo, ela iria caracterizar-se pelos recursos financeiros exíguos, para colocar em prática as políticas propostas e, consequentemente, a construção insuficiente de unidades, diante da crescente demanda por moradia entre a população de baixa renda.

Entre as décadas de 1950 e 1960 do século XX, cresceu substancialmente os investimentos estatais e estrangeiros na economia brasileira, atrelado ao crescimento da população urbana. Apesar destas transformações no campo social e econômico no país, o período do Governo Kubitscheck (1956-1961) ficou marcado pela falta da devida importância à questão habitacional. O resultado mais uma vez, foi a manutenção de uma política de habitação popular pífia e a falta de uma política efetiva de atendimento à crescente demanda.

Diante desse quadro, a questão urbana passou a ser debatida como uma questão social efetiva no início dos anos 1960, a partir da defesa da reforma urbana. O ápice destas discussões foi a reunião realizada no Hotel Quitandinha, no Rio de Janeiro, em 1963, encontro que contou com a participação de diversos profissionais que trabalhavam com 
a questão urbana, tendo sido esta a primeira mobilização em defesa da reforma urbana (BRASIL/MCID, 2004).

A partir do aprofundamento das discussões e, consequentemente, como forma de minimizar a tensão social, foi criado durante a ditadura militar (1964) o Banco Nacional de Habitação (BNH), tendo o Fundo de Garantia por Tempo de Serviço (FGTS) como o principal financiador do BNH. Os objetivos na época eram exatamente minimizar o grande déficit habitacional que existia no Brasil, estando estruturado sistematicamente da seguinte maneira: as Companhias Habitacionais (COHABs) seriam responsáveis pelo atendimento às famílias de baixa renda, as Cooperativas Habitacionais (INOCOOPS), atenderiam as famílias com renda mensal de 3 a 6 salários mínimos e as Caixas Econômicas, Associações de Poupança e Empréstimos e Sociedade de Crédito Imobiliário, estariam destinadas às famílias com rendas mínimas de 6 salários mínimos (LEHFELD, 1988).

Mesmo com a introdução da política habitacional e, posteriormente, com suas respectivas mudanças, o BNH chegou ao seu fim em 1986 não conseguindo atender efetivamente as camadas mais populares (entre 0 e 3 salários mínimos), fato decorrente das contradições entre dois objetivos: o de estimular o desenvolvimento econômico e o atendimento às camadas mais baixas da população (CARDOSO, 2002). É preciso levar em consideração também a conjuntura econômica do país: recessão, inflação, renda excessivamente baixa para este grupo de famílias, burocracia e dificuldade para as famílias se encaixarem nos programas, número de unidades inferior à demanda, entre outros fatores.

Diante dessa situação, os excluídos do acesso à moradia, em sua maioria as famílias de baixa renda que não se inseriam nos pilares de financiamento, promoveram a construção de moradias informais ou a promoção das ocupações, que cresceram substancialmente nas décadas seguintes. A esta realidade, soma-se a falta de assistência médica, saneamento básico, creches e áreas de lazer e a ausência do Estado, cujas características interferiam diretamente na habitabilidade das pessoas e no viver digno.

\section{3 - Aspectos norteadores e a lógica do PMCMV}

Após o fim do Banco Nacional de Habitação (BNH), o país evidenciou pequenas mudanças na política destinada à moradia popular, especialmente nos dois mandatos de 
governo de Fernando Henrique Cardoso (1995-2002). Destacam-se alguns avanços que vão desde a concepção da cidade enquanto função social a diversidade de programas, construídos ao longo dos anos da gestão (MARICATO, 1998). Por outro lado, é preciso evidenciar que este período foi, também, de redefinição da política habitacional brasileira, no que concerne a maior participação da iniciativa privada e na alocação de recursos públicos para o setor da construção civil ${ }^{3}$.

Com a vitória do Partido dos Trabalhadores (PT) à presidência da República, através de Luís Inácio Lula da Silva, várias ações foram colocadas como metas, para que o projeto de redefinição das políticas públicas e diminuição do déficit habitacional fossem concretizados.

Ainda durante o período de campanha eleitoral à presidência da República em 1994, já se discutia em seu programa, a necessidade de democratização do espaço urbano, do combate ao déficit habitacional e da criação de um ministério com finalidade específica, órgão administrativo foi batizado de "Ministério das Cidades". Este Ministério ficou responsável pela formulação de uma ação planejadora, normativa e articuladora no que concerne à questão urbana (BRASIL/MCID, 2004).

Os programas federais, a partir da aprovação do Plano Nacional de Habitação (PNH) e da criação do Sistema Nacional de Habitação de Interesse Social (SNHIS), dividiram-se em dois grandes eixos de atuação: urbanização de assentamentos precários e produção habitacional (BRASIL/MCID, 2010). Outro instrumento criado pelo plano foi o Sistema Nacional de Habitação, que definia o processo de participação da iniciativa privada na produção de moradias no país. Este instrumento foi proporcionado a partir de dois subsistemas: o Subsistema de Habitação de Interesse Social e o Subsistema de Habitação de Mercado. Enquanto o primeiro direcionava os recursos públicos exclusivamente para a população de baixa renda, através do FGTS e do FNHIS, o segundo subsistema reorganizava o mercado privado, ampliando as formas de captação de recursos e a inclusão de novos agentes que facilitasse a promoção imobiliária, através da caderneta de poupança e demais instrumentos de atração dos investidores (SHIMBO, 2010).

\footnotetext{
${ }^{3}$ Shimbo (2010) destaca que houve uma mudança de "paradigma" após 10 anos do fim do BNH, ou seja, houve a introdução na política habitacional brasileira, princípios de mercado na aquisição da habitação. Ampliando, desta forma, o setor privado, a descentralização da alocação dos recursos federais e uma política introdutória de crédito para o mutuário final.
} 
Para que as metas do subsistema de habitação de interesse social fossem cumpridas, foram firmadas parcerias com os estados e municípios, tendo o Ministério das Cidades como o principal agente articulador e gestor dos programas habitacionais, com diferentes fontes de recursos: FGTS, Orçamento Geral da União (OGU), Fundo de Arrendamento Residencial (FAR) e Caixa Econômica Federal, operando o sistema (op. cit., 2010).

Shimbo (2010), através de seu trabalho de tese questiona a contradição existente, nos recursos destinados ao subsistema de habitação de interesse social, pois: mesmo sendo um subsistema específico para a população de faixa de renda de até 3 salários mínimos, há a prerrogativa de atendimento às famílias com renda acima deste patamar, cujos limites seriam 12 salários mínimos, além disso, os proponentes podem ser empresas do setor da construção civil ou pessoas físicas, através dos recursos do FGTS. Adiante a autora conclui:

Este último aspecto indica a contradição existente na própria concepção do Subsistema de Habitação de Interesse Social, pois abre o caminho para a entrada de agentes privados (com fins lucrativos) nas linhas de financiamento, alimentadas por recursos onerosos vindos do FGTS. Desta forma, a segmentação das fontes de recursos, anunciada na proposta da Política Nacional de Habitação, se dilui, obscurecendo os limites entre os dois subsistemas idealizados (Ibid, 2010, p. 82).

O subsistema de mercado também sofreu alterações para dar maior garantia ao mercado imobiliário, já que a concessão de crédito imobiliário passou a ser uma atividade altamente lucrativa. Através da Política Nacional de Habitação (PNH) o governo Lula tomou algumas medidas importantes: a primeira foi a de promover a segurança jurídica e econômica ao mercado privado em 2004, cujos intuitos eram o combate à inadimplência dos mutuários e a livre atuação dos capitais de origem imobiliária, a segunda foi a criação de novos títulos de crédito e a ampliação de recursos financeiros ao mercado privado ${ }^{4}$ (Ibid. 2010).

\footnotetext{
4 Royer (2009) explica os fatores convergentes para o recente boom imobiliário, ou seja, em apenas 5 anos (2003 a 2008), a contratação com recursos do SBPE multiplicou em 8 vezes, entre os fatores apontados estão: maior segurança jurídica para os incorporadores, melhoria do crédito para a pessoa física, com redução da taxa de juros, aumento do prazo de pagamento e diminuição do valor da entrada, além da redução da taxa de juros.
} 
Cardoso \& Aragão (2013) citam ainda as alterações nas medidas fiscais e a aprovação da MP 252 em 2004, que ampliou a segurança dos investidores do setor imobiliário, utilizando a alienação fiduciária nas transações imobiliárias e da instituição do principio do "patrimônio de afetação".

Houve ainda outros estímulos como a redefinição da política de desoneração físcal e a de reordenação na legislação que desencadeou o fortalecimento do setor privado na construção e incorporação das moradias, a redução do Imposto sobre Produtos Industrializados (IPI) para materiais de construção civil, a facilidade de financiamento pelo BNDES para as empresas que solicitam empréstimos para construção de habitações, além da redução dos encargos sobre os lucros. Estes estímulos facilitaram significativamente o aumento dos lucros das empresas de construção civil e do setor imobiliário (SILVA, 2012).

Todas estas ferramentas foram fundamentais para a ampliação do setor, o fortalecimento das empreiteiras e a redefinição do mercado de habitação no país ${ }^{5}$. Como explica sinteticamente Shimbo (2010):

Resumidamente, ao longo do período entre 2004 e 2006, as medidas regulatórias que estimularam diretamente a produção de habitação via mercado foram; a) estímulo ao financiamento imobiliário, reduzindo os juros pagos aos bancos sobre depósitos não utilizados para financiamento dentro do SFH e exigindo que, no mínimo, $65 \%$ dos depósitos em contas de poupança sejam utilizados para esse fim; b) simplificação e intensificação da aplicação das leis de reintegração de posse de propriedade residencial no caso de inadimplência (alienação fiduciária); c) diminuição do IPI (Imposto sobre Produtos Industrializados) sobre certos insumos e materiais de construção; d) fomento para a securitização de recebíveis imobiliários através da isenção de impostos de renda sobre ganhos financeiros advindos dessa transação; e) aumento da segurança de empreendedores através da disponibilização de garantias sobre prosperidade e de compradores através do regime tributário especial (SHIMBO, 2010, p. 92).

Na mesma linha adotada pelo governo Lula a partir de 2004, no que se refere ao aumento de recursos destinados ao financiamento habitacional e nos incentivos fiscais, foi criado o Programa Minha Casa Minha Vida (PMCMV). Gestado em março de 2009, este programa foi fruto de uma intervenção estatal, juntamente com a iniciativa privada,

\footnotetext{
5 A partir de 2004, algumas empresas do setor imobiliário realizam operações na Bolsa de Valores, cujos recursos são utilizados para ampliar suas atividades, investindo em terras ou financiando novos empreendimentos, desenvolvendo a financeirização do setor no país (CARDOSO \& ARAGÃO, 2013).
} 
no sentido de "deter" a forte crise econômica que tinha assolado os principais países capitalistas do mundo em 2008, após a desestruturação financeira e imobiliária nos EUA. Neste sentido, o principal objetivo desta intervenção era investir no mercado habitacional e tentar conter a crise (BONDUKI, 2009).

O programa baseou-se em dois pilares fundamentais: estimular o desenvolvimento do setor da construção civil e o crescimento de emprego e da economia do país, este último aspecto seria favorecido, essencialmente pelo consumo. Neste sentido, o governo desencadeou uma série de iniciativas, que iam desde o barateamento das taxas de juros à criação de um Fundo Garantidor de Habitação (FGHAB), estabelecendo como meta o atendimento de 3,4 milhões de famílias até $2014^{6}$.

Inserido no PNH, foi elaborado o Plano Nacional de Habitação (PlanHab), cuja proposta baseava-se no planejamento das ações públicas e privadas, em médio e longo prazo, para equacionar as necessidades habitacionais do país no prazo de quinze anos (BONDUKI, 2009). Apesar deste plano ter sido construído com uma maior participação popular (movimentos sociais, profissionais, governos estaduais e municipais), levando em consideração a diversidade dos municípios brasileiros e uma maior participação e controle social nas políticas públicas de habitação, ele foi suplantado pelo Programa Minha Casa Minha Vida (PMCMV), cujos mecanismos de elaboração estiveram a cargo dos Ministérios da Casa Civil e da Fazenda, em diálogo com representantes da construção e sem participação popular (SOUZA, 2009; FIX, 2011).

O PMCMV definiu que há dois grupos de famílias que podem ter acesso à moradia, o primeiro é para as famílias com renda de até 3 salários mínimos que podem ser atendidas com até $100 \%$ de recursos do Orçamento Geral da União (OGU), gastando $5 \%$ da renda familiar (com mínimo de $\mathrm{R} \$ 25,00$ por mês) para pagamento de 120 prestações mensais. Os subsídios chegam a ultrapassar $90 \%$ do valor do imóvel. Para as famílias com renda de até $\mathrm{R} \$ 1.600,00$, estabeleceu-se inicialmente a meta de contratação de 400 mil unidades habitacionais, com a continuidade do programa a meta passou para 860.000 unidades habitacionais até o ano de 2014, para operações contratadas com recursos do FAR (BRASIL, 2014).

\footnotetext{
${ }^{6}$ De acordo com os dados divulgados pela Caixa Econômica Federal em 2010, a meta 1 milhão de habitações construídas foi ultrapassada naquele mesmo ano (BRASIL/MCID, 2010).
} 
As famílias precisam se inscrever junto às prefeituras dos municípios onde residem. Após o processo seletivo que são feitos com base nos critérios estabelecidos pelo Ministério das Cidades e pelo próprio município, os órgãos encaminharão os tramites necessários para a aquisição dos imóveis. Para as famílias que com renda acima de 3 salários mínimos, os interessados devem procurar diretamente as construtoras, que comercializam imóveis enquadrados no PMCMV, e a CAIXA para avaliar as condições de obtenção do financiamento e conseguir os respectivos subsídios.

Estas duas modalidades há o indicativo de participação das construtoras, que podem firmar parcerias com estados, municípios e movimentos sociais (modalidade Minha Casa Minha Vida Entidades), paralelamente, a CEF analisa os projetos, contrata a operação, acompanha a execução da obra pela construtora, libera recursos e, ao final da construção realiza a comercialização dos imóveis. Os financiamentos são incorporados aos subsídios, que podem ser entre $60 \%$ a $90 \%$ do valor do imóvel, cuja prestação se restringe a $10 \%$ da renda pelo prazo de 10 anos (BRASIL, 2014).

Quanto aos participantes do programa, estão divididos da seguinte forma: Caixa Econômica Federal, instituição de caráter financeiro que é responsável pela definição dos critérios técnicos, dos atos para operacionalização do Programa; Ministério das Cidades estabelece diretrizes, regras, condições, define a distribuição dos recursos entre as Unidades da Federação e avalia o Programa; Ministério da Fazenda: rever juntamente com o Ministério das Cidades, o limite de renda familiar dos beneficiários e a remuneração da CAIXA; Distrito Federal, Estados e Municípios ou órgãos que aderirem ao Programa: sua participação é efetivada através do termo de adesão com a Caixa, definindo áreas priorizadas para implantação dos projetos, isenção de tributos, aporte de recursos, indicação de demandas, indicação de solicitantes para a venda dos empreendimentos e execução do trabalho Técnico Social junto aos beneficiários; Empresas da construção civil: apresentam projetos, tendo sua aprovação efetivada executa-os na forma estabelecida pelo Programa, além de guardar os imóveis prontos e legalizados pelo prazo de 60 dias (SHIMBO, 2010).

Foi estabelecida ainda, uma tipologia mínima para apartamentos do programa: 02 quartos, sala, cozinha, banheiro e área de serviço, transição com área útil mínima de 37 $\mathrm{m}^{2}$ e acessibilidade com área útil mínima de $39 \mathrm{~m}^{2}$, cujos valores máximos por unidades habitacionais estão estabelecidos por estado/localidades e, por tipologias diferenciadas 
em casa e apartamento, apresentadas por portarias do Ministério das Cidades (abril e agosto de 2013).

Apesar do avanço significativo de combate ao déficit habitacional no Brasil e, o aporte financeiro, caracterizado por virtuosas somas aos programas habitacionais, atingindo a população mais necessitada, ou seja, entre 0 e 3 salários mínimos, Cardoso \& Aragão (2013) sintetizam as críticas feitas por especialistas ao programa, entre elas estão:

(i) a falta de articulação do programa com a política urbana; (ii) a ausência de instrumentos para enfrentar a questão fundiária; (iii) os problemas de localização dos novos empreendimentos; (iv) excessivo privilégio concedido ao setor privado; (v) a grande escala dos empreendimentos (vi) a baixa qualidade arquitetônica e construtiva dos empreendimentos; (vii) a descontinuidade do programa em relação ao SNHIS e a perda do controle social sobre a sua implementação. A esses pontos, já destacados por várias análises, acrescentamos ainda (viii) as desigualdades na distribuição dos recursos como fruto do modelo institucional adotado (CARDOSO \& ARAGÃO, 2013, p.44).

Estes pontos reafirmam o caráter da implantação da política habitacional nos últimos tempos no Brasil: especialmente quando não há mecanismos claros de combate à estrutura fundiária urbana, à ausência de mecanismos de controle e participação social, além dos empreendimentos atenderem a uma lógica mercantil, em que a população com menores patamares de renda, se distribui nas periferias (a periferização dos empreendimentos), locais estes, carentes das mínimas condições de habitabilidade, paralelamente, em algumas capitais como Rio de Janeiro, o mercado imobiliário foi impulsionado pela organização dos mega-eventos, exercendo influência no deslocamento da população no ambiente intra-urbano, através da gentrificação de áreas destinadas a grandes equipamentos urbanos (CARDOSO et al., 2013) ${ }^{7}$.

Portanto, é perceptível que a organização e execução deste programa estiveram eminentemente ligadas a uma estratégia econômico-financeira e corporativa, extraídos dos gabinetes e órgãos governamentais, juntamente com a participação efetiva da iniciativa privada, desta forma, o caráter de uma habitação popular no Brasil, ganha contornos difusos e privatistas, ao passo que a condição ideológica de conquista da

\footnotetext{
${ }^{7}$ Para uma análise aprofundada do PMCMV, consultar o trabalho: O Programa Minha Casa Minha Vida e seus efeitos territoriais (2013). Ver referências.
} 
habitação não se efetiva pelo direito essencialmente, mas introjetado pela busca frenética de capitais e sua acumulação a partir de um bem essencial, a moradia.

\section{4 - Grandes eventos esportivos e dinâmica imobiliária: O PMCMV em São Lourenço da Mata-Pe}

O município de São Lourenço da Mata está localizado na mesorregião Metropolitana e na Microrregião Recife do Estado de Pernambuco, limita-se ao norte com o município de Paudalho, ao sul com Jaboatão dos Guararapes e Moreno, a leste com Recife e Camaragibe e a oeste com Vitória de Santo Antão e Chã de Alegria (CPRM/PRODEEM, 2005).

Por possuir certa proximidade com a capital do estado (aproximadamente $18 \mathrm{Km}$ ), há um estímulo à interligação nos diversos setores como transporte, serviços e emprego. Estes aspectos contribuem para que haja uma forte migração diária de pessoas que realizem algum tipo de atividade em Recife, seja na escolarização, na procura de setores públicos específicos, em vínculos empregatícios ou mesmo na procura de centros de comércio e lazer, cujos portes ou especificidades se encontram na capital.

O município foi criado em 13 de junho de 1884, pela Lei Provincial Número 1807, tendo sido desmembrado de Recife e Paudalho e sendo formado pelos distritos Sede e Nossa Senhora da Luz. De acordo com o censo 2010 do IBGE, a população total era de 102.895 habitantes, com projeção de ultrapassar os 110 mil, no ano de 2015. Numa densidade habitacional de $362,106 \mathrm{Hab} / \mathrm{Km}^{2}$, deste total mais de $90 \%$ se localizam em áreas urbanas. A principal atividade econômica do município é o setor de serviços, com uma representação de $60 \%$ do produto interno. O PIB per capita é considerado um dos piores da Grande Recife (IBGE, 2015).

Apesar do crescimento populacional nos últimos anos, as condições socioespaciais do município ainda são precárias. Ainda há uma forte desigualdade nos aspectos mais básicos de atendimento à população como saneamento, transporte público, educação, condições de habitabilidade, entre outros. O resultado é inserção do município entre os mais pobres da Região Metropolitana do Recife (Ibid. 2015).

Nos últimos anos, São Lourenço da Mata ficou nacionalmente conhecida por abrigar uma das arenas que recebeu jogos da Copa das Confederações em 2013 e Jogos da Copa 
do Mundo em $2014^{8}$. Em virtude da repercussão que este empreendimento traria para o município e, consequentemente para a Grande Recife, a proposta inicial do governo, incluía ainda a criação de uma nova centralidade na zona oeste da RMR, em virtude do crescimento exarcebado da capital, mais especificamente nas zonas norte e sul (áreas que concentram bairros altamente populosos).

Mello (2015) apresenta três elementos importantes para a escolha do projeto no município: a função estratégica na escala metropolitana, a criação de uma nova centralidade e a participação da iniciativa privada no empreendimento. Paralelamente, foi apresentada, em diversos segmentos da comunicação, através de imagens e maquetes a Cidade da $\mathrm{Copa}^{9}$, a primeira cidade "inteligente da América Latina", cujo espaço abrigaria faculdades, prédios residenciais e comerciais, shopping, condomínios clubes, prédios públicos, parques, rede de transporte com ciclofaixas e um sistema de infraestrutura e imobiliário urbano altamente avançado, no que se refere à tecnologia de ponta, sendo amplamente divulgada como a primeira cidade inteligente do Brasil. Tudo isso, girando em torno da Arena Pernambuco (Figura 01).

Ao mesmo tempo, o plano incluía a reformulação dos transportes públicos locais, com a construção dos chamados BRT (Bus Rapid Transit), que pretendia mudar a mobilidade da cidade, através da readequação de diversos corredores, inclusive o Leste-Oeste (que vai desde o centro do Recife até o município vizinho a São Lourenço, denominado Camaragibe), mais especificamente o que dá acesso à Arena Pernambuco e aos diversos bairros de São Lourenço da Mata.

\footnotetext{
${ }^{8}$ Inicialmente o Governo de Pernambuco lançou um projeto que previa a construção de uma arena multiuso entre as cidades de Olinda e Recife, entretanto, o projeto é substituído pela Arena Pernambuco e Cidade da Copa em São Lourenço da Mata e em 31 de maio de 2009 a FIFA anuncia as cidades-sedes. Houve ainda o comprometimento pelo governo de aceleração das obras para receber a Copa das Confederações em 2013, fato confirmado pela FIFA em 20 de outubro de 2011.

9 Amplamente divulgado pelo Governo do estado de Pernambuco, através de uma Parceria Público Privada com a Odebrecht, a Cidade da Copa foi um empreendimento concebido para ser "uma cidade inteligente", ou seja, o empreendimento reuniria tanto o conceito de desenvolvimento urbano moderno como o respeito à sustentabilidade ambiental. Para isso, haveria uma central de monitoramento, onde os recursos energéticos seriam gerenciados (uso eficiente de água, energia e gás), de modo que seu reaproveitamento fosse um ato intrínseco ao projeto. A Cidade foi dividida em quatro eixos: moradia, trabalho, educação e entretenimento, com previsão de conclusão até 2025. Entretanto, diante da crise nacional, o envolvimento da empreiteira (Odebretch) em casos de corrupção e a crítica situação em que passa as finanças do estado, o projeto parece ser definitivamente esquecido, uma vez que o valor investido seria em torno de 1,6 bilhão. Mais informações, ver caderno especial sobre um ano após o mundial de 2014 no Brasil: http://especiais.ne10.uol.com.br/foi-mais-que-7x1/
} 
Figura 01 - Imagem de divulgação do Projeto Cidade da Copa

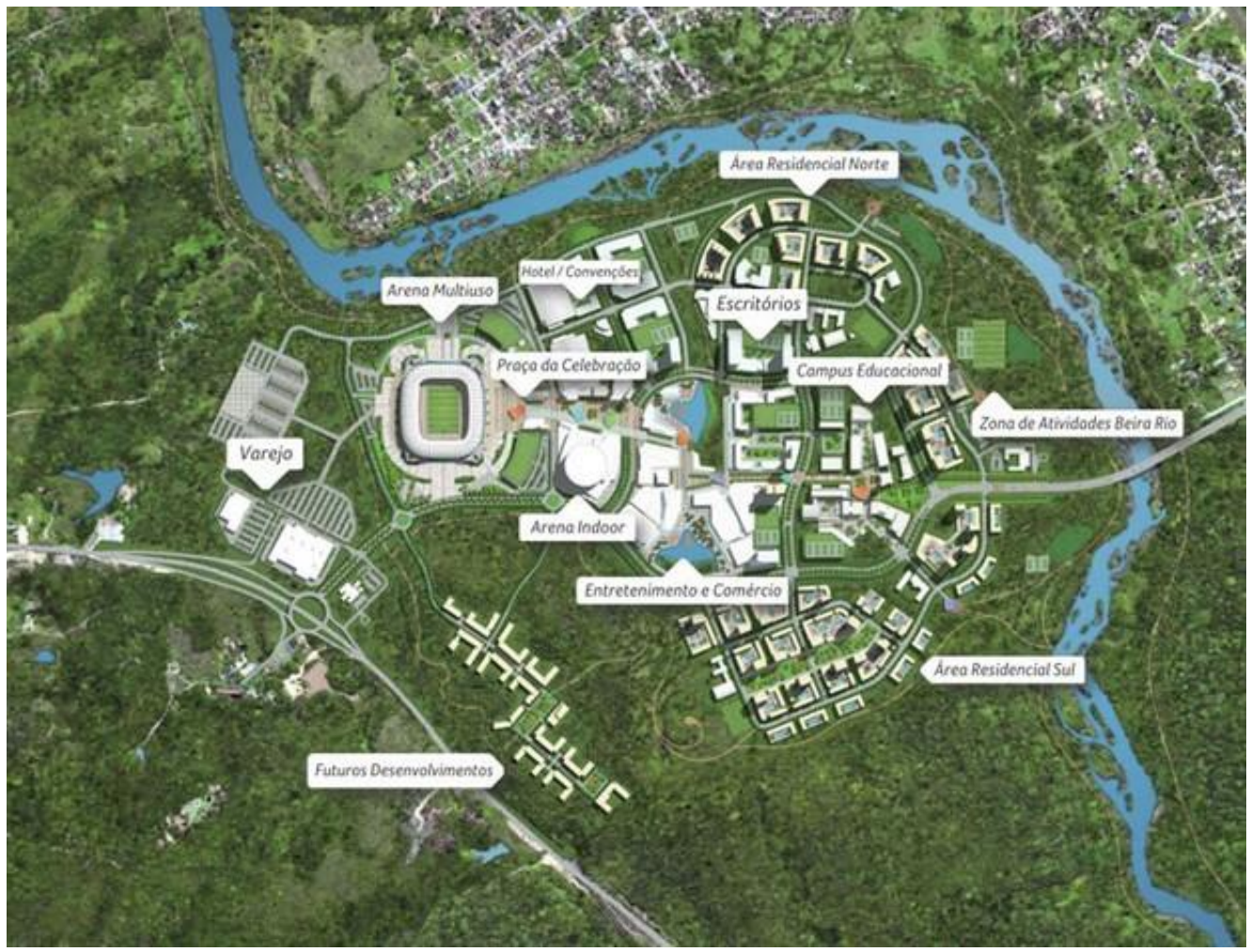

Fonte: Odebretch e Governo do Estado (2011).

Além da construção de paradas de ônibus com sistema informatizado e ar-condicionado, o plano previa a ampliação de um terminal de passageiros moderno e confortável, para isso, foram desapropriadas cerca de 400 famílias de uma área próxima à estação de metrô de Camaragibe ${ }^{10}$.

Vale salientar que grande parte das famílias que foram desapropriadas não receberam indenizações ainda, em função das questões burocráticas ou jurídicas, ou ainda receberam uma indenização bem abaixo do que o imóvel realmente valia na prática ${ }^{11}$.

10 Porém, mais de um ano após a previsão de entrega das obras, o terminal de passageiros não foi construído, tendo o terreno desapropriado cedido a uma empresa de transporte privada para evitar novas ocupações, ao mesmo tempo, muitas das estações sequer foram entregues à população, especialmente, às que cortam o município de Camaragibe, inviabilizando que a população tenha acesso ao sistema fora da estação.

${ }^{11}$ Sobre as contradições no que se refere às indenizações ver os dados colhidos pelo site do Jornal do Commercio em sua edição especial on line em junho de 2015, junto à Defensoria Pública e Procuradoria Geral do Estado. Das famílias atingidas pela desapropriação, apenas $44 \%$ receberam $100 \%$ da indenização, enquanto que $26,68 \%$ receberam $80 \%$ e $9,17 \%$ ainda não receberam nada (DANTAS e WAGNER, 2015). Ver referências. 
Todos estes atrativos urbanísticos e de mobilidade, atrelado à construção da Arena Pernambuco e o recebimento das Copas da Confederação e do Mundo, divulgado nos mais variados meios de comunicação, fez crescer enormemente os interesses das construtoras, das mais diversas empresas dos setores imobiliários, direcionando naquela época, os investimentos para o município, especialmente em áreas próximas ao estádio e à "Cidade da Copa" (G1, 2013).

Tal interesse confluía ainda com a localização do município (no centro da RMR), a disponibilidade de terras e a forte participação do Estado, inclusive com a flexibilização do Plano Diretor municipal, desta maneira, as áreas destinadas à construção de Habitação de Interesse Social (HIS), por exemplo, transformaram-se em Zona de Urbanização Preferencial (MELLO, 2015).

Paralelamente, as famílias vislumbravam uma propaganda massiva destas mesmas empresas, que destacavam o "viver bem", longe do centro urbano e da agitação. Um local para moradia aprazível, envoltas por áreas verdes, com a possibilidade de estarem próximos de grandes empreendimentos imobiliários, acessibilidade e transporte "eficiente". Para que estes elementos ideológicos pudessem funcionar como fatores significativos, o sistema de marketing e o simbolismo em torno desses "benefícios", promulgado pelas construtoras, funcionavam em vários meios de comunicação, como panfletos, redes sociais, propagandas de rádios e TVs (Ibid, 20015).

Estes fatores suscitaram também, o interesse em investimentos e a procura pela acumulação de renda em meio à elevação dos preços dos imóveis e a relativa estabilidade financeira, ao passo que diversos investidores, desde as mais importantes corporações imobiliárias até as famílias que se integravam à classe média, pudessem adquirir um imóvel seja para alugar, para a compra e venda ou mesmo para a especulação imobiliária, como mostra a tabela a seguir, no aumento do número de empreendimentos no município (Tabela 01).

Houve, portanto, um crescimento substancial de empreendimentos que aderiram ao PMCMV ao longo de sete anos no município, totalizando cerca de 5224 unidades construídas ou em processo de finalização. O empreendimento lançado ainda em 2008, foi um dos primeiros no município que conseguiu a adesão, logo após o anúncio do programa em março de 2009. 
Tabela 01 - Empreendimentos e descrições

\begin{tabular}{|l|c|c|c|}
\hline EMPREENDIMENTO & UNIDADES & CONTRUTORA & $\begin{array}{c}\text { ANO DO } \\
\text { LANÇAMENTO }\end{array}$ \\
\hline Privê Solar Mont Blanc & 320 & Prolar & 2008 \\
\hline $\begin{array}{l}\text { Residencial Jardim São } \\
\text { Francisco }\end{array}$ & 224 & Lógica & 2009 \\
\hline $\begin{array}{l}\text { Residencial Vila } \\
\text { Capibaribe }\end{array}$ & 06 & VL Construtora & 2010 \\
\hline Residencial Vila Bela & 20 & VL Construtora & 2011 \\
\hline $\begin{array}{l}\text { Residencial Bosque Pau Brasil } \\
\text { Alameda Residencial }\end{array}$ & 80 & $\begin{array}{l}\text { TeS Construções } \\
\text { e Incorporações }\end{array}$ & 2011 \\
\hline $\begin{array}{l}\text { Residencial Vila do } \\
\text { Campo }\end{array}$ & 104 & Nacional & 2011 \\
\hline $\begin{array}{l}\text { Residencial Parque } \\
\text { Capibaribe }\end{array}$ & 256 & $\begin{array}{l}\text { TeS Construções } \\
\text { e Incorporações }\end{array}$ & 2012 \\
\hline Reserva São Lourenço & 2.048 & $\begin{array}{c}\text { Pernambuco } \\
\text { Construtora }\end{array}$ & 2012 \\
\hline Reserva Atlântica Jatobás & 448 & Nacional & 2012 \\
\hline $\begin{array}{l}\text { Reserva Atlântica } \\
\text { Palmeiras }\end{array}$ & 334 & Nacional & 2012 \\
\hline Residencial Vila da Copa & 20 & VL Construtora & 2012 \\
\hline Residencial Vila luz & 40 & VL Construtora & 2013 \\
\hline $\begin{array}{l}\text { Reserva Atlântica } \\
\text { Figueiras }\end{array}$ & 448 & Nacional & 2013 \\
\hline Residencial Vila Nova & 44 & VL Construtora & 2014 \\
\hline $\begin{array}{l}\text { Condomínio clube Vila } \\
\text { Verde }\end{array}$ & 432 & VL Construtora & 2015 \\
\hline $\begin{array}{l}\text { Reserva Atlântica } \\
\text { Jacarandás }\end{array}$ & 384 & Nacional & 2015 \\
\hline
\end{tabular}

Fonte: Construtoras e trabalho de campo (2015).

O pico de unidades lançadas aconteceu no ano de 2012, potencializada pelo momento propício da economia e estabilidade da moeda brasileira, pelo incremento do mecanismo de propaganda pelas construtoras e pela própria demanda do mercado. Só neste ano, o número de unidades lançadas totalizou 964, especialmente por apartamentos com dois quartos, sala para dois ambientes, cozinha, área de serviço e banheiro, com uma dimensão em torno de $45 \mathrm{~m}^{2}$, cuja média de preços aumentou significativamente. Em 2012 foi o ano com a maior alta do mercado, chegando a 100 mil reais o preço médio de um apartamento simples, enquanto que no ano de 2009 , o mesmo apartamento podia ser adquirido por um preço médio de 50 mil reais, já com o 
subsídio do Governo. Portanto, um aumento médio de 100\% em seu valor em apenas três anos, para apartamentos com o mesmo padrão, na qual foi especificado anteriormente.

A distribuição espacial segue o perfil, especialmente da localização, ou seja, a proximidade da Arena e da Cidade da Copa foram elementos importantes utilizados no sistema de marketing das principais construtoras para vender as unidades habitacionais (ver exemplo da figura 02).

Figura 02 - Folheto de divulgação de uma das construtoras atuantes no município

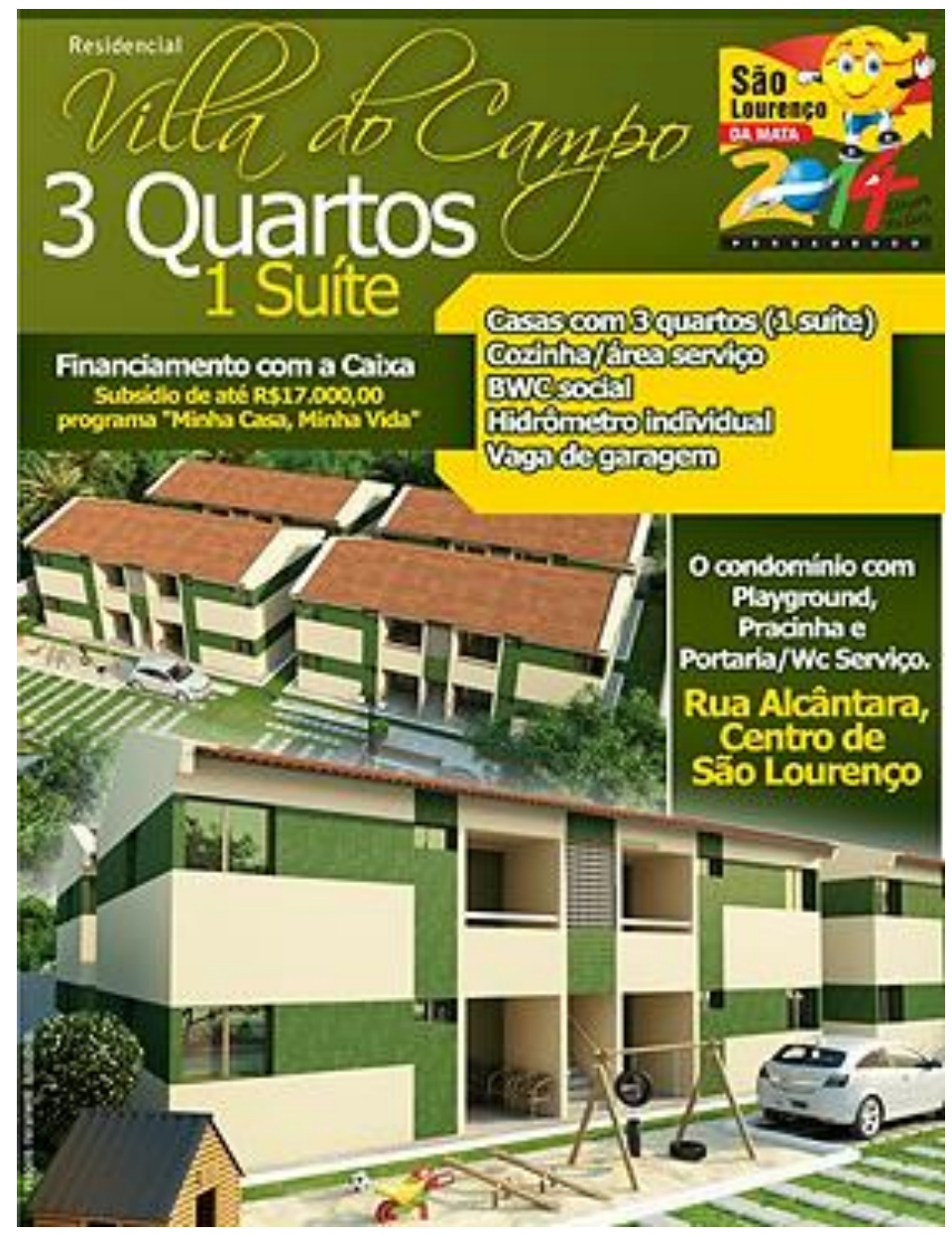

Fonte: TeS Construções e Incorporações (2015).

Alguns empreendimentos seguem a perspectiva de um bairro planejado, como forma de suprir a ausência ou a distância do comércio, bancos ou serviços. Estes bairros foram comercializados com o oferecimento de todas estas benesses dentro do chamado "condomínio-clube", sem necessariamente se deslocar para a centralidade mais próxima, ou seja, uma nova lógica do mercado imobiliário para atrair mais clientes. 
Entretanto, muitos destes empreendimentos não surtiram o efeito desejado, é o caso do Reserva São Lourenço, construído na BR 408, a cerca de 4 Km da Arena Pernambuco. Com uma estimativa de antecipar um futuro desenvolvimento, muitos adquiriram imóveis deste empreendimento, pela proximidade do estádio e da futura "cidade inteligente", hoje, com o abandono do projeto Cidade da Copa pelo Governo estadual e a dificuldade de mobilidade pelos moradores, atrelado à crise na economia do país, os preços do aluguel caíram significativamente ${ }^{12}$, outros sequer se mudaram, preferindo esperar a retomada da economia para negociar o imóvel.

Este quadro retrata a conjuntura que passa o país na atualidade, calcula-se que, de acordo com o Índice Fipezap, os imóveis no Brasil perderam 5\% do valor em 2015 (ALMEIDA, 2015). Esta tendência repercutiu diretamente no mercado imobiliário da Grande Recife, especialmente no setor da construção civil, responsável pela demissão de diversos trabalhadores. Neste sentido, comprar ou alugar um imóvel ficou muito mais difícil, por outro lado, o preço do aluguel teve uma redução ao longo dos últimos meses (G1, 2015).

A distribuição espacial dos empreendimentos nos mostra a proximidade com a arena e, consequentemente, com a Cidade da Copa (Figura 03). Cujos preços dos imóveis sofreram alterações à medida que havia uma maior procura, estimulada pela proximidade do mundial e pelas projeções lançadas pelo Governo estadual de melhoria no sistema de transporte público, mobilidade e a construção de uma nova centralidade. Todos estes elementos eram divulgados para a grande mídia pela empresa responsável (Odebrecht), como um avanço e um modelo urbano inovador, no que concerne à gestão de cidades, ou seja, ela estaria inserida num contexto de desenvolvimento, influenciadas pelas grandes cidades mundiais.

Neste sentido, a propaganda e a consolidação de mecanismos administrativos das cidades, estão baseados na racionalidade e no empreendedorismo, onde a gestão e inserção da iniciativa privada, através das Parcerias Público-Privadas (PPP), tornaramse uma constância nos dias atuais (HARVEY, 2005; SOUZA, 2006; SILVA, 2015). E foi com esta visão que a propaganda foi exercida em torno da construção da "cidade inteligente", cujos espaços seriam permeadas por "espetáculos”, receptoras de grandes

12 Ver disponibilidade de imóveis para alugar neste empreendimento, com preços abaixo da média, se comparados com apartamentos, com mesmo padrão, em outros municípios da RMR. http://www.vivareal.com.br/aluguel/pernambuco/sao-lourenco-da-mata/apartamento_residencial/ 
intervenções urbanas que aquecem o mercado imobiliário, fazendo com que áreas antes esquecidas, sejam vislumbradas como um novo "nicho de mercado" seja para a classe popular ou para a classe com mais poder econômico.

Figura 03 - Distribuição espacial dos principais empreendimentos (2008 a 2015).

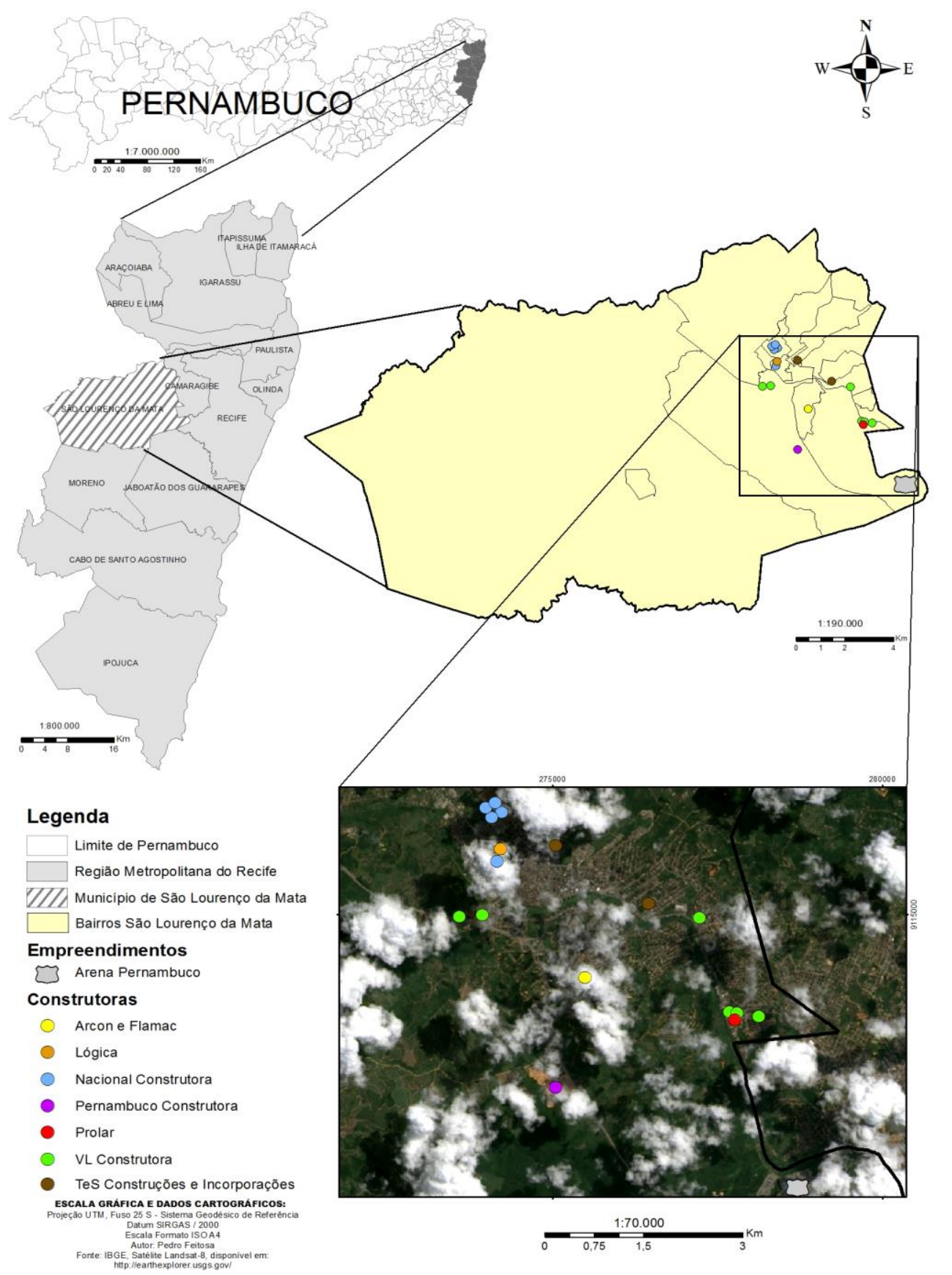

Fonte: IBGE. Malhas digitais (2010); Imagens Google (2015). 
Desta forma, o PMCMV, desde sua formulação e seu lançamento em 2009, obedeceu a um padrão de "socorro" ao setor da construção civil e enfrentamento da crise de 2008 , inclusive com um estreitamento entre o Estado e as maiores empresas do ramo como a RMV, Rossi e Cyrela, além disso, a mudança ministerial, ou seja, a substituição do então Ministro Olívio Dutra (PT) por Márcio Fortes (PP) aprofundou o distanciamento com os setores populares e o alinhamento com o setor empresarial, transformando a política em cunho econômico e não-social (LOUREIRO et. al., 2013).

O PMCMV no município de São Lourenço da Mata foi beneficiado por esta redefinição das políticas públicas de "habitação popular" em cunho nacional, ancorada ao mesmo tempo pelo papel das construtoras e os benefícios concedidos pelas políticas de caráter mercadológico, paralelamente, o discurso era amparado no desenvolvimento local, cuja promoção estava a cargo dos órgãos públicos. Outros mecanismos de caráter ideológico, baseou-se num sistema de propaganda de atração do consumidor, ou seja, a disponibilidade de um ambiente aprazível para as famílias, a proximidade da Cidade da Copa e um sistema de transporte eficiente que seria instalado, tudo isso, com uma incisiva participação dos Governos municipal e estadual.

\section{5 - Considerações finais}

A gestão das cidades brasileiras, especialmente, que sofreram intervenções e grandes projetos urbanos, são permeadas por ações articuladas e cada dia mais estreitas entre o setor privado e o Estado, cuja materialização deste processo é a consolidação das chamadas Parcerias Público-Privadas (PPP). Os grandes eventos esportivos que aconteceram e virão a acontecer no Brasil, são elementos claros deste processo. $\mathrm{O}$ fato é que estas intervenções terminam por movimentar vários setores, inclusive o setor imobiliário.

A consolidação da cidade de São Lourenço da Mata como receptora de uma arena multiuso e a possível construção de uma "cidade inteligente", denominada Cidade da Copa, com a reestruturação do sistema de transporte do município e a disponibilidade de terras para a construção e expansão urbana, fez com que as incorporadoras e construtoras do ramo imobiliário investisse suas atenções no novo nicho de mercado, tendo como benefício as ações articuladas nas três esferas de governo, ou seja, na esfera federal houve toda a mudança legislativa no que concerne a política pública de 
habitação através do PMCMV, como redução de impostos, seguridade ao construtor, subsídios e a segurança jurídica e financeira ao mercado privado, na esfera estadual houve a consolidação da PPP na construção da arena e na possível construção da Cidade da Copa. O estado ainda foi responsável pela duplicação da BR que dava acesso à arena e na "melhoria" do sistema de transporte, na esfera municipal, houve a redefinição urbanística que permitia a construção de imóveis, em locais antes denominados de interesse social.

Portanto, a força articulada em vários setores, amparada pela legislação urbanística e demais políticas públicas, desencadeou o crescimento imobiliário através do PMCMV no município de São Lourenço da Mata. A ação dos mecanismos de marketing promovidos pelas empresas do setor da construção civil, ajudaram no aumento substancial da procura. Entretanto, muitos destes empreendimentos que foram aprovados com a anuência do governo local, sofrem com a ausência das condições mais básicas como saneamento e acessibilidade.

Desta forma, a análise crítica das políticas habitacionais é fundamental para sua verdadeira democratização, de maneira que haja uma maior participação dos setores mais carentes e que o caráter mercadológico não sobressaia na configuração espacial, em detrimento de uma cidade justa e para todos.

\section{REFERÊNCIAS}

ALMEIDA, M. Imóveis no Brasil perdem $5 \%$ do valor em 2015. Revista Exame. São Paulo, 05 de agosto de 2015. Disponível em: < $\underline{\text { http://exame.abril.com.br/seu- }}$ dinheiro/noticias/imoveis-no-brasil-perdem-5-do-valor-em-2015. Acesso em: 07 de novembro de 2015.

AZEVEDO, S. D.; ANDRADE, L. G. D. Habitação e poder. Rio de Janeiro: Zahar, 1982.

BOLAFFI, G. Habitação e urbanismo: o problema e o falso problema. In: A produção capitalista da casa (e da cidade) no Brasil industrial. São Paulo: Ômega, 1979.

BONDUKI, G. N. Origens da habitação social no Brasil: arquitetura moderna, lei do inquilinato e difusão da casa própria. 4. Ed. São Paulo: Estação Liberdade, 2005.

, G. N. Do Projeto Moradia ao programa Minha Casa, Minha Vida. Teoria e Debate, nº 82, maio/junho. 2009.

BRASIL, Ministério das Cidades. Cadernos Mcidades: participação e controle social. Brasília, 2004. 
BRASIL. Caixa Econômica Federal. Programa Minha Casa Minha Vida. Brasília, 08 de outubro de 2014. Disponível em: <http://www1.caixa.gov.br/gov/gov_social/municipal/programas_habitacao/pmcmv/sai ba_mais.asp > Acesso em: 20 de outubro de 2015.

BRASIL. Ministério das Cidades. Minha casa minha vida supera 1 milhão de moradias. Brasília, 29 de dezembro de 2010. Assessoria de comunicação. Disponível em: <http://www.cidades.gov.br/noticias/minha-casa-minha-vida-supera-1-milhao-demoradias> Acesso em: setembro de 2015.

CPRM - Serviço Geológico do Brasil. Projeto cadastro de fontes de abastecimento por água subterrânea. Diagnóstico do município de São Lourenço da Mata, estado de Pernambuco / Organizado [por] MASCARENHAS, J. C., BELTRÃO, B. A., SOUZA JUNIOR, L. C. de, GALVÃO, M. J. T. G., PEREIRA, S. N., MIRANDA, J. L. F. de,. Recife: CPRM/PRODEEM, 2005.

CARDOSO, A. L. Política habitacional no Brasil: Balanço e perspectivas. Proposta, Rio de Janeiro: $\quad$ Fase, $30 \quad$ (95), http://www.ippur.ufrj.br/observatoriodasmetropoles, 2002.

CARdoso, A. L.; ARAGÃO, T. A.; ARAúJO, F. S. SILVA, N. F.; D. R. N, JUNIOR.; T. P. AMORIM. Minha Casa Minha Sina: implicações da recente produção habitacional pelo setor privado na Zona Oeste da cidade do Rio de Janeiro. In: CARDOSO, A. L. (Org.). O Programa Minha Casa Minha Vida e seus efeitos territoriais. Rio de Janeiro: Letra Capital, 2013.

DANTAS, M. WAGNER, T. Especial: Foi mais que 7x1. NE10. Recife, 13 de julho de 2015. Disponível em: <http://especiais.ne10.uol.com.br/foi-mais-que7x1/expediente.php> Acesso em: 20 de novembro de 2015.

FIX, M. Financeirização e transformações recentes no circuito imobiliário no Brasil. Tese (Doutorado em Desenvolvimento Econômico) - Instituto de Economia/Unicamp, Universidade de Campinas, 2011.

G1. Crise provoca baixa em vendas de imóveis no Grande Recife. G1. Recife, 22 de maio de 2015. Disponível em: <http://g1.globo.com/pernambuco/noticia/2015/05/criseprovoca-baixa-em-vendas-de-imoveis-no-grande-recife.html $>$ Acesso em: 20 de novembro de 2015.

G1. Investimentos do setor imobiliário crescem em São Lourenço, PE. G1. Recife, 26 de junho de 2013. Disponível em: <http://g1.globo.com/pernambuco/noticia/2013/06/investimentos-do-setor-imobiliariocrescem-em-sao-lourenco-pe.html> Acesso em: 10 de outubro de 2015.

GOULART, D. C. O anticapitalismo do Movimento dos Trabalhadores Sem-Teto MTST. 242 f. Tese (Doutorado em Ciências Sociais) - Universidade Estadual Paulista, Faculdade de Filosofia e Ciências, Marília, 2011.

HARVEY, D.. A Produção capitalista do espaço. São Paulo, Anna Blume, 2005. 
IBGE - Instituto Brasileiro de Geografia e Estatística. Informações sobre os municípios brasileiros. Rio de Janeiro: IBGE, 2015. Recuperado em 13 de janeiro de 2016, Disponível em: <http://www.cidades.ibge.gov.br/xtras/home.php> Acesso em: 20 de dezembro de 2015.

LEHFELD. N. A. de S., Uma abordagem populacional para um problema estrutural: a habitação. Rio de Janeiro: Vozes, 1988.

LOUREIRO, M. R.; MACÁRIO, V.; GUERRA, P. Democracia, arenas decisórias e políticas públicas: o Programa Minha Casa Minha Vida. Texto para Discussão. Instituto de Pesquisa Econômica Aplicada.- Brasília : Rio de Janeiro: IPEA, n. 1886, p. 7-33, 2003.

MARICATO, E., Política urbana e de habitação social: um assunto pouco importante para o governo FHC. Revista Praga, São Paulo, 1(6), p. 67-68, 1998. Disponível

em: <http://www.fau.usp.br/depprojeto/labhab/biblioteca/textos/maricato_politicaurbanafhc. pdf> Acesso em: 16 de janeiro de 2016.

MELLO, G. M. S. de., Transformações na dinâmica territorial de São Lourenço da Mata: da "cidade da copa" aos novos empreendimentos imobiliários. Dissertação (Mestrado em desenvolvimento Urbano) - Programa de Pós-Graduação em Desenvolvimento Urbano/UFPE, Recife, 2014.

RODRIGUES, A. M., Moradia nas cidades brasileiras. 10. Ed. São Paulo: Contexto, 2003.

ROLNIK, R., A cidade e a Lei: legislação, política urbana e territórios na cidade de São Paulo. São Paulo: Fapesp, 1997.

ROYER, L. Financeirização da política habitacional: limites e perspectivas. Tese (Doutorado em Arquitetura e Urbanismo) - Faculdade de Arquitetura e Urbanismo, Universidade de São Paulo, São Paulo, 2009.

SIQUEIRA, M. P. S. Habitação popular: a materialização da casa própria no Brasil. Dimensões, 21, 2008. Disponível em: <http://www.periodicos.ufes.br/dimensoes/article/viewFile/2491/1987> Acesso em: 05 de novembro de 2016.

SILVA, C. F. da., O Movimento de Luta nos Bairros, Vilas e Favelas (MLB) e a política de autogestão: análise de uma experiência no bairro da Iputinga, RecifePe. Dissertação (Mestrado em Geografia) - Universidade Federal da Paraíba, João Pessoa, 2012.

O capitalismo monopolista e a renda da terra urbana na cidade mercadoria: uma discussão sobre o empreendimento "Novo Recife". Revista Pegada Eletrônica, Presidente Prudente, SP, 16 (01), 225-249, jan./jun, 2015. Disponível em: <http://revista.fct.unesp.br/index.php/pegada/article/view/3348/3024> Acesso em: 15 de janeiro de 2016. 
SOUZA, M. A. A., Pensando a política nacional de habitação para a diversidade das famílias e dos municípios brasileiros. In: Bitoun, J., Miranda, L. (orgs). Desenvolvimento e Cidades no Brasil: contribuições para o debate sobre as Políticas Territoriais. Recife: FASE: Observatório das Metrópoles, 2009.

SOUZA, M. L. de., Cidades, globalização e determinismo econômico. Cidades: Revistas Científica/Grupo de Estudos Urbanos, Presidente Prudente, SP, v. 3, n. 5, p. 123-142, jan./jun, 2006. Disponível em: <http://revista.fct.unesp.br/index.php/revistacidades/article/view/507> Acesso em: 20 de novembro de 2016.

SHIMBO, L. Z., Habitação social, habitação de mercado: a confluência entre Estado, empresas construtoras e capital financeiro. Tese (Doutorado em Arquitetura e Urbanismo) - Faculdade de Arquitetura e Urbanismo, Universidade de São Paulo, São Carlos, 2010. 